Artículo

\title{
Desarrollando valores a través de la educación
}

\author{
Developing values through education \\ Milton Ascencio Velásquez \\ milton.ascencio@udb.edu.sv
}

ISSN 1996-1642, Editorial Universidad Don Bosco, año 9, No.15, enero-junio de 2015, pp. 7-21 Recibido: 1 de octubre de 2014. Aprobado: 2 de febrero de 2015.

\section{Resumen}

La idea principal en este artículo es que la educación y los educadores deben contribuir con la formación de valores a través de la creación de espacios para el diálogo y el consenso, los cuales permitan ejercitar valores tales como la reflexión crítica, la tolerancia y el respeto en situaciones que los estudiantes enfrentan en el día a día. Se argumenta que el enfoque funcionalista-tradicional que caracteriza la educación actual es incapaz de formar en valores pues no promueve la reflexión crítica que permitiría la toma de decisión y la actuación autónoma. Basado principalmente en el trabajo de Graham Haydon, se presentan ideas relacionadas con los valores y la moral. Además, se propone que los valores y la moral deben ser parte del proceso de aprendizaje mediante el diálogo y el consenso para enfrentar el conflicto.

Palabras clave: valores, moral, conflicto, diálogo, consenso.

* El Autor es Director de la Escuela de Idiomas de la Universidad Don Bosco y estudiante del Doctorado en Educación de la Universidad de Costa Rica, Costa Rica.

Para citar este artículo: Ascencio, M. (2015). Desarrollando valores a través de la educación. Diál-ogos 15, 7-21.

\section{Abstract}

The main idea in this article is that both education and educators should contribute to the formation of values through the generation of spaces for dialogue and consensus in order to practice critical reflection, tolerance, and respect in situations that students face every day. It is argued that the functionalist-traditional approach that characterizes education at present hinders the formation of values since it does not foster critical reflection for independent decision-making and action. Primarily based on Graham Hayon's work, this article presents some ideas related to values and morals. Furthermore, it is proposed that values and morals should be part of the learning process through dialogue and consensus in order to deal with conflict.

Keywords:values, morals, conflict, dialogue, consensus. 


\section{Introducción}

En los últimos años se ha elevado el clamor y el reclamo por una sociedad sin violencia. Esto deviene por una situación de descomposición social e inseguridad que han crecido en forma alarmante en El Salvador. Día tras día los medios de comunicación informan sobre altas cifras de muertes violentas, violaciones, robos, extorsiones y toda clase de males mientras que las instituciones encargadas de garantizar la seguridad parecen impotentes ante una ola de violencia de grandes magnitudes. Basta con caminar por las calles de las principales ciudades del país para enterarse de la desconfianza en los ojos de muchas personas quienes apresuran su paso para escapar de una amenaza. Frente a un panorama tan desagradable, no han faltado los cuestionamientos a la educación y el trabajo que en las instituciones educativas realizan los educadores, mientras que se argumenta que esta situación decadente es el resultado de una educación falta de valores humanos.

Otros, por el contrario, piensan que referirse a una educación para la formación en valores es vacío, contradictorio e incluso hipócrita. Hace algunos años Savater (2002) señalaba que hablar de valores puede llegar a parecer excesivamente edificante y moralizante, pues la situación actual no hace más que generar un sentimiento de decepción y contradicciones. Se habla de solidaridad en una sociedad plagada de explotación. Se habla de sinceridad cuando la falsificación propagandística y tendenciosa inunda los medios de comunicación y las redes sociales. Se promueve la tolerancia en una sociedad en la que predomina el fanatismo político y religioso que induce a la violencia y la discriminación de género. No obstante, si el mundo y nuestra sociedad fueran tan buenos (una sociedad solidaria, sincera y tolerante) no haría falta hablar sobre valores ni siquiera pensar que la educación pudiera promover valores.

Este ensayo está estructurado en seis secciones. En la primera sección trata sobre el propósito de la educación y se cuestiona la finalidad de la educación funcionalista-tradicional. En la segunda sección se apuntan las percepciones que se tienen sobre la educación y los educadores en relación con la formación en valores. La tercera sección explica el término valores y presenta algunas percepciones que se tienen al respecto. En la cuarta sección se aborda el conflicto y en qué medida los valores morales reducen o generan conflicto. La quinta sección trata sobre la moral y sobre la motivacional moral como una alternativa a la educación funcionalista. En la última sección se argumenta en favor de la necesidad del diálogo y el consenso para la formación en valores.

\section{Educar, ¿para qué?}

Para los educadores tradicionales y funcionalistas, el rol principal de la educación es la socialización. La socialización ha de entenderse como mecanismos y sistemas externos de transmisión de convicciones, creencias y valores comunes que garanticen la continuidad de una sociedad (Levine, 2010; Sacristán y Pérez, 2003). Sacristán y Pérez comentan que cuando la sociedad se complejizó, el proceso de socialización pasó de formas secundarias de educación (tutor, 
preceptor, etc.) a sistemas de escolarización obligatoria con la finalidad de preparar el ciudadano para su futura inserción en la sociedad. Estos dos autores apuntan que la escuela tiene dos funciones principales en el proceso de socialización. Primero, preparar a las personas para su incorporación al mundo del trabajo mediante conocimientos, destrezas, disposiciones, actitudes, intereses y modos de conducta requeridos. Segundo, preparar el ciudadano para que participe de la vida adulta y pública mediante la inculcación de valores, normas de comportamiento y de convivencia que la sociedad espera. No obstante, Levine (2010) observa que si bien es cierto que la socialización es un medio que asegura la cohesión social para que la sociedad funcione, no menos cierto es que también llega a ser un medio para alcanzar el control social y el adoctrinamiento.

Se debe resaltar la importancia que para los funcionalistas, y en el proceso de socialización, representan los mecanismos y sistemas externos de transmisión, inculcación, preparación e inserción del futuro ciudadano en la sociedad. Los mecanismos funcionalistas-tradicionales de la educación pretenden regularizar y uniformar el comportamiento y el pensamiento de los estudiantes mediante la formación de hábitos y la disciplina. En este proceso, el profesor podría incluso ostentar una investidura sagrada e infalible tal y como Durkheim (1947) lo asumía al decir que "lo mismo que el pastor es el intérprete de Dios, él [el profesor] es el inspirador de las grandes ideas morales de su tiempo y de su país. . . puesto que él las expresa y las encarna a los ojos de los niños" (p. 175). Sólo de esta forma, según se explica, el profesor sentará las bases de una sociedad democrática, el respeto a la ley, la legalidad y el orden.

Pareciera que una de las debilidades de la concepción tradicional-funcionalista es precisamente su incapacidad de hacer que los estudiantes se vuelvan agentes de transformación social y promotores de una sociedad más justa y humana, caracterizada por la solidaridad, la tolerancia y la convivencia armónica. De una educación funcionalista con mucha certeza se tendrán ciudadanos disciplinados, obedientes a las reglas, buenos trabajadores; aunque quizá acríticos e incapaces de someter dogmas y creencias a la comprobación o cuestionar instrucciones aun cuando tengan el propósito de hacer daño a otras personas. De una educación funcionalista se esperaría una sociedad que no cree conflicto. Por el contrario, sería una sociedad que no vea el conflicto como fuente de transformación social. De una educación funcionalista se esperaría la continuidad de lo existente, más de lo mismo. Si la función de la educación es sólo transmitir las conquistas de la humanidad, sus valores, formas de conducta y habilidades para el trabajo, entonces esa función se limita a mantener y perpetuar un cierto tipo de orden social, aun si fuera perverso. Al ocuparse por trasladar lo que la sociedad adulta espera, el énfasis de una educación funcionalista no es puesto en la transformación de la persona ni en la transformación social, sino en la consolidación de las condiciones sociales actuales aunque estas se caractericen por la pobreza, la violencia, las desigualdades y la exclusión. 
Una educación funcionalista erosiona la capacidad para desarrollar la actuación y el pensamiento autónomo. Para el funcionalista, el profesor es quien tiene la autoridad de hace valer su voz mientras que los estudiantes deben escuchar y someterse a las instrucciones y reglas institucionales. Son las instituciones, los programas de estudio y los profesores quienes determinan qué pensar y creer sin posibilidad de que los estudiantes tengan la oportunidad de cuestionar su legitimidad y veracidad. Las instituciones educativas serían una especie de fábrica que produce ciudadanos autómatas o robots políticos, burocráticos y tecnoplásticos, como le llama Azofeifa (1979), quienes aprenden el hábito de la obediencia y la disposición para someterse a condiciones y decisiones impuestas sin capacidad de analizar la pertinencia de estas para el bienestar colectivo. De tal manera que las prácticas pedagógicas y rutinas escolares en una educación basada en la transmisión, la imitación, la repetición (memorización y automatización) así como el reforzamiento son más útiles por la uniformidad de comportamientos y pensamiento que producen que por la promoción de la diversidad y la diferencia que caracterizan a la especie humana.

No es necesario hacer una extensa investigación para darse cuenta que tales ideas y prácticas pedagógicas se han arraigado profundamente en la educación tradicional hasta estos días. La experiencia misma da cuenta de cómo una educación funcionalista ha caracterizado la práctica educativa que ha orientado la función de nuestra práctica pedagógica por largo tiempo. Como bien observa Ferraz Lorenzo (2012) sobre tal tipo de educación, "su función tradicional ha sido la de mantener el orden social dominante y la estabilidad política para asegurar su preservación y equilibrio a través del conocimiento transmitido de generación en generación" (p. 7). Lo anterior ya habría sido apuntado hace algunas décadas por Azofeifa (1979), quien se lamentaba "por la absoluta falta de fines formativos de nuestra enseñanza oficial. Nuestros jóvenes salen del bachillerato ignorando totalmente el mundo en que viven y más los valores que en nuestro tiempo se debaten" (p. 38).

Entonces, ¿cuál podría ser la función de una educación pertinente para esta sociedad? Se podría argumentar que la función de la educación, más que perpetuar el orden social existente o preparar a las personas para el campo laboral, es asegurar y mejorar la calidad de vida de cada persona y de la sociedad en general. El mejorar la calidad de vida se traduce en la posibilidad no sólo de alcanzar el acceso a la salud, garantizar la alimentación y el bienestar familiar, sino también asegurar el respeto a la vida, la solidaridad, la tolerancia y la convivencia. Se sostiene aquí que para asegurar y mejorar la calidad de vida de las personas también se necesita un tipo de educación que tenga como uno de sus fines la construcción de valores a partir de la generación de espacios para la deliberación, el diálogo y el consenso sobre los problemas del día a día que interesan a la sociedad. Tal idea se ubica en la misma línea de Haydon (2003) para quien "la educación está especialmente relacionada con el conocimiento y el entendimiento, la racionalidad y un tipo de apreciación más elaborado y refinado, tanto del mundo natural como de las creaciones humanas, que sólo se hace posible mediante la educación" (p. 41). 
La realidad de la educación actual, sin embargo, demuestra lo contrario por lo que convendría revisar y replantear qué estamos brindando a los estudiantes en las aulas. Ya sea porque la educación actual no haya sido pensada para ello, porque la educación no pueda contrarrestar la influencia que la familia y el entorno tengan en las personas o porque los docentes no estén preparados para llevar a cabo esa función, lo evidente es que actualmente la educación aún no ha logrado hacer prevalecer valores que promuevan la solidaridad, la tolerancia, la convivencia y la armonía en la sociedad. No se trata de adjudicar únicamente a la educación la misión de salvar esta sociedad del caos social en el que se encuentra sumergida, pues es probable que al responsabilizar a la educación de transformar la sociedad las expectativas estén lejos de lo que realmente se puede hacer desde las aulas. Se trata de volver la mirada a aquello que como educadores sí se puede hacer desde la educación en términos prácticos para contribuir con la transformación de esta sociedad.

\section{La formación en valores, ¿quién es responsable?}

Existe una tendencia en la sociedad a dirigir una mirada inquisidora hacia la educación y señalar su responsabilidad cada vez que hay situaciones de conmoción pública. Cuando los casos de corrupción, asesinato, aborto o acciones violentas alcanzan a los medios de comunicación, la opinión pública se ve conmocionada y no falta quienes responsabilizan a la educación por el tipo de comportamiento antisocial o por la carencia de valores. Esto es así porque se da por sentado que gran cantidad de cosas importantes en la vida dependen del tipo de educación recibida. Por lo mismo, las personas tienen la posibilidad de enjuiciar la carencia de valores o expresar su aprecio hacia estos porque la educación ha puesto el tema de valores al alcance de las personas. En este proceso de enjuiciamiento o apreciación, el rol de los profesores en la construcción de valores humanos no está exento de interpretaciones por parte la sociedad.

Para muchos, aunque no para todas las personas, no hay duda de que los docentes son los encargados de transmitir valores en nombre de la sociedad entera. Al respecto, Haydon (2003) observa que "todavía sigue considerándose a los maestros como guías y ejemplos morales, cuyas normas están, quizá, algo por encima del nivel del resto de la sociedad" (p. 23). Pareciera que, para muchos en la sociedad, los docentes han sido investidos por una capacidad especial y extraordinaria que les faculta para volverse un dechado de virtud y un modelo de rectitud al frente los estudiantes. Sin embargo, habría que preguntar a los docentes si están de acuerdo con esa percepción o, en todo caso, si están de acuerdo en asumir tal responsabilidad. En el caso que los educadores estén convencidos de que esa es una de sus funciones también habría que preguntarles si están preparados metodológicamente para realizar tal función. Sería interesante indagar en qué medida aquellos de quienes se espera que formen en valores en la sociedad han tenido preparación efectiva en el tema. No se trata sólo de saber y conocer al respecto, sino también tener la preparación metodológica adecuada en cuanto a cómo formar en valores sin que suscite la idea de que se busca la imposición. Aún más, habrá que analizar hasta qué punto los programas de estudio incluyen la preparación académica para tal fin. 
También hay muchos que preferirían que la educación y los educadores evitaran la formación en valores y se enfocara únicamente en la preparación de los alumnos para su inserción en la vida laboral. En todo caso, la preparación para la vida laboral es algo que la educación formal reclama como una de sus funciones en la sociedad y esto no parece implicar mayor discrepancia. Es posible que quienes no comparten la opinión de que las instituciones educativas se involucren en la formación en valores sostengan esa postura por desconocer a qué se refieren los valores o por no saber cómo la educación puede contribuir en dicha formación de manera efectiva sin que ello implique la imposición de ideas. Antes de discutir si la educación formal debe asumir tal responsabilidad y cómo hacerlo, es necesario discutir un poco más sobre qué son los valores y algunas percepciones al respecto. Comprender en qué consisten los valores permitirá definir una posición frente al dilema sobre si las instituciones educativas y los educadores deberían o no contribuir con ello y cómo hacerlo.

\section{3. ¿Qué son los valores?}

Ante la pregunta ¿qué se entiende por valores?, a muchos les parecerá más fácil dar ejemplos de valores que brindar una definición. El término valor casi siempre se asocia con acciones de rectitud, virtud, cualidades del carácter y condiciones de vida a las que las personas suelen dar importancia en la sociedad. Por un lado, Gevaert (2008) define el valor como "todo lo que se cree relevante para realizar la existencia humana, todo lo que permite dar un significado a la existencia humana" (p. 184). Para este autor, los valores sólo adquieren existencia cuando se expresan de algún modo en el mundo concreto. Un ejemplo de estos son los valores artísticos los cuales existen porque se concretizan en campos como la literatura y la poesía. De igual manera, los valores humanos existen porque se concretizan en la relación intersubjetiva. Haydon (2003), por otro lado, argumenta que los valores -todo lo que adquiere un valor para las personas- pueden ser concretos o abstractos. Esto es porque no sólo se confiere valor a las propiedades y pertenencias materiales en el sentido que se cuidan y se aprecian, sino que las personas también aprecian y valoran cualidades o ideas abstractas e intangibles tales como la honestidad, la tolerancia, la lealtad y la seguridad.

Con frecuencia se cree que si una sociedad desarrolla valores, sus miembros tendrán una conducta ideal y en armonía con los demás. Posiblemente esta idea es el resultado de asociar los valores con una conducta intachable e impregnada por la rectitud; aunque no siempre ha sido así. La obediencia, por ejemplo, es algo que ha llegado a adquirir mucho valor en nuestra sociedad, aunque ello no siempre ha resultado en acciones de bien. Se ha de recordar que durante la guerra civil de los años ochentas en El Salvador, el ejército armado cometió muchas masacres y atrocidades contra la población civil inocente mientras obedecían las órdenes de sus superiores. En este caso, se habría preferido que los soldados nunca hubieran desarrollado la obediencia como un valor dentro de un régimen militar. Dado ese contexto, la obediencia no parece adquirir un valor positivo, al menos no para quienes hayan padecido el agravio militar. 
Los valores están asociados a una serie de normas y motivaciones que les relaciona de forma directa con el comportamiento, la moral y la religión. Por una parte, Gevaert sostiene que toda acción humana está constituida por tres momentos: la motivación, la decisión y la ejecución. Estos momentos permiten conjeturar, de alguna manera, qué está detrás de un comportamiento. Por ejemplo, sería posible decir que una persona o una sociedad es tolerante o intolerante, no porque se autocalifiquen como tal, sino porque sus comportamientos y acciones demuestran estar motivados, o no, por la tolerancia. En esa misma línea, Haydon (2003) dice que "los valores reales de las personas se demuestran en lo que hacen, dado que, cuando hablan sobre sus valores, las personas pueden ser poco sinceras o autocomplacientes" (p. 53).

Por otra parte, cuando se habla de valores, es muy común que las personas tiendan a relacionarlos con la moral y esta última con la religión. Haydon (2003) aclara que "lo que convierte en morales los puntos de vista de una persona no es, por decirlo así, su contenido superficial, sino los tipos de razones con los que la persona los apoye" (p. 54). Aunque más adelante se abordará el tema, por el momento sirve decir que la moral es un conjunto de normas que regulan la convivencia en la sociedad y que van en la línea del deber ser. Las personas pueden llegar a pensar que deben hacer algo porque eso es bueno o que no deben hacerlo porque eso es malo. Más aún, muchas veces pensar que algo está bien o mal suele estar acompañado de creencias religiosas, condicionando al individuo para que actúe de una u otra manera, aunque eso vaya contra su naturaleza o en contra de lo que conviene hacer en una situación dada. Quizá por esa asociación con la religión y sus creencias es que hay personas que no aprueban el que las instituciones educativas y sus profesores se involucren en la formación de valores, pues suponen que es mejor evitar que se inculquen ciertas ideas con las cuales no se tiene afinidad. No tiene por qué ser así.

Todas las personas, seguidores de una religión o no, tienen valores morales. Se dijo antes que un valor puede llegar a ser moral en parte debido a las razones sobre las cuales se fundamenta. Al respecto, Haydon (2003) señala que para quienes siguen una religión el que algo vaya en contra del orden divino es suficiente razón para ser moralmente malo mientras que para un no creyente la maldad moral está determinada por hacer un bien o un daño a otro ser humano. Si este razonamiento es acertado, sería difícil encontrar una persona sin valores. Es más, sería difícil que alguien no tenga valores morales, que no sea capaz de diferenciar la bondad de la maldad, la compasión de la tortura o la protección del abuso de un menor indefenso, con limitaciones físicas o mentales. Por tanto, la diferencia entre uno y otro tipo de valor radica en la motivación subyacente, no en qué es bueno o qué es malo según una tendencia religiosa. Aún así, existe controversia entre qué está bien o qué está mal al punto de considerar que los valores son subjetivos o relativos y que, por tanto, es irrelevante que se aborden desde la educación.

Decir que los valores son subjetivos y relativos puede causar un poco de confusión. Según Gevaert (2008), se debe distinguir entre las cosas que portan 
el valor (lo objetivo) y la cualidad del valor conferida a esas cosas (lo subjetivo). Para este autor, aunque se confiere valor a una cosa, ese valor no constituye una propiedad inherente de esa cosa, sino que las cosas adquieren valor en la medida que pasan a formar parte de la actividad humana. Por un lado, Haydon (2003) sugiere que el carácter objetivo de los valores se verifica a partir de que su veracidad o falsedad no se determina por lo que la gente piensa o sienta acerca de tal o cual valor ni por lograr ponerse de acuerdo, o no, sobre alguno de estos. Al contrario, el hecho de que haya desacuerdo demuestra que hay algo objetivo que motiva el diálogo y que está allí para ser reconocido o rechazado. Lo subjetivo, por otro lado, deviene del hecho de que cada persona tiene la capacidad de generar su propio punto de vista sobre una situación dada. En tal sentido, Gevaert (2008) sostiene que el ser humano tiene la cualidad fundamental de ser sensible ante los valores así como de otorgar valor a las cosas. Gracias a esa sensibilidad se es capaz de emitir juicios de valor sobre acciones para la realización del ser humano y sobre otras acciones que van en contra de ella.

La idea de que todos los valores son relativos también merece ser analizada. Para muchos, ser relativo significa que todo depende del punto de vista de cada persona y que cada persona tiene una apreciación particular sobre un valor. Al respecto, Haydon (2003) explica que la expresión relativo significa que los valores se conciben con respecto a (en relación con) un contexto, una tradición o una cultura. Sobre la dimensión cultural, Gevaert (2008) señala que los valores no son fijados de forma arbitraria por cada persona, sino que se insertan en una cultura y adquieren una cualidad para unos y otros en tanto que se sirven para reconocer al otro. Un ejemplo del carácter relativo de un valor es el otorgado a la libertad de las mujeres en la cultura occidental en comparación con la que se tiene en las culturas semíticas. De allí que cómo se valore la libertad de las mujeres será relativo a (en relación con) la cultura o momento histórico desde el cual se haga la valoración. Por lo anterior, decir que los valores son relativos no equivale a decir que todos los sujetos tienen opiniones particulares sobre los valores.

Además hay quienes piensan que existen valores universales y que por lo tanto todos en el mundo deben reconocerlos. Desafortunadamente la historia brinda evidencia para decir que no todas las personas en el mundo reconocen un valor como la paz, pues se empeñan en hacer guerras y conflictos. Mientras que todos en el mundo tienen derecho a vivir en paz, este valor no es reconocido ni aplicado por todos. Por ello sería más apropiado entender el carácter universal de un valor en el sentido que éste debe ser aplicado a todas las personas. Ahora, ¿qué se puede decir cuando el conflicto o la violencia tienen su origen en los valores?

\section{Los valores, ¿resuelven el conflicto?}

Al ver tanta violencia en la sociedad se tiende a pensar que la naturaleza humana es la autodestrucción y destruir lo que está a su alrededor. Haydon (2003) retoma una idea similar del escritor Hobbes para quien "los seres humanos, abandonados a sus propios recursos, llevarían una vida repugnante, brutal y 
corta... siendo como es la condición humana, la posibilidad de conflictos está siempre presente y hay que contenerla" (p. 65). La pregunta que muchos harían es cómo contener o reducir estos conflictos. Una posible respuesta es a través de la formación en valores morales.

Se podría argumentar que los valores morales contribuyen en la reducción del conflicto. Al respecto, Haydon (2003) entiende que la moral es "ese conjunto de valores que es necesario para contener el conflicto potencial: consiste en las prohibiciones básicas de matar, atacar, robar, mentir, incumplir promesas y cosas por el estilo; o puede comprender un conjunto de virtudes de carácter general" (p. 66). De la cita anterior se infiere que un mayor fortalecimiento de los valores morales permitiría reducir el nivel de conflicto. Sin embargo, no está claro cómo conciliar esa declaración con el hecho de que los valores también son causa de conflicto.

Los valores originan conflicto cuando los puntos de vista o formas de vida se ven enfrentados. Hay situaciones en las cuales los puntos de vista de una minoría se enfrentan a los de la mayoría. Lo anterior se refleja en las acciones reivindicativas de los grupos feministas y homosexuales. En tales casos, el conflicto no suele llegar hasta la violencia o al menos no sobrepasar el ataque verbal. No obstante, otras experiencias como la esclavitud o el racismo hacia los afroamericanos en los Estados Unidos han provocado muertes y guerras. En estos casos no parece que las personas perciban los valores morales como una cuestión de subjetividad o una mera preferencia. Si así fuera, no habría conflictos pues cada uno sería libre de pensar y actuar independiente de las preferencias de otros. El problema es que, como apunta Haydon (2003), "la diferencia de valores morales son, en cierta medida, diferencias de formas de vida, y las diferencias de formas de vida son una fuente de conflictos más poderosa que las diferencias de opinión como tales" (p. 69). La situación se agrava cuando los valores adquieren significados absolutistas para una persona hasta el punto de asumir que quienes no piensen igual están equivocados. Esto puede provocar intolerancia hacia quienes no piensen o actúen de la misma manera.

Aunque los valores generan conflicto, este último es necesario. De no haber sido por el conflicto de valores, la abolición de la esclavitud o la afirmación de los derechos de los afroamericanos en los Estados Unidos no habrían tenido lugar. Asimismo, el conflicto generado por los valores ha permitido que las sociedades modernas en nuestra región sean menos machistas que en el pasado con un progresivo reconocimiento de los derechos de las mujeres así como menos intolerantes hacia la diversidad de género. Incluso, el lenguaje ha experimentado algunos cambios orientados a la inclusión de género. No existe razón para que el conflicto sea sinónimo de violencia.

El conflicto se puede resolver a través del diálogo. Según Haydon (2003), cuando hay disputas morales, la forma de resolverlos es mediante el diálogo para encontrar lo que es beneficioso para todos. No se trata de truncar la autonomía del otro, sino dar razón de los intereses particulares con el propósito 
de encontrar la mejor solución que beneficie a todos y así reducir el conflicto. Si bien se acepta que los valores morales son necesarios para reducir el conflicto, también se acepta que la moral por sí misma no es garantía de solución sin el diálogo o el consenso entre las personas. Una postura diferente a esta es la que sostiene que es mejor hablar de diálogo más que de moral. De hecho, no faltan quienes proponen evitar el término moral, moralidad y valores morales en la educación.

\section{La moral, ¿se debería enseñar?}

Muchos docentes sentirán que han sido contratados para desarrollar destrezas laborales específicas o enseñar un área del saber muy particular, pero no para enseñar moral por lo que podrían incomodarse si se les pide hacer eso. Es probable que tal renuencia tenga que ver con lo que se entiende por la moral. Por un lado, si moral tiene que ver con ser un ejemplo de virtud ante los demás y con tener que convertirse en una especie de juez de lo que está bien o está mal, entonces pocos querrán asumir tal responsabilidad. Por otro lado, si la moral se asocia con el sexo y las preferencias sexuales de las personas, y además promover ideas al respecto, el problema se agrava. La simple asociación de enseñar moral con inculcar y promover ideas, hasta imponer ideas, no parece ser una función agradable. Se debe reconocer, sin embargo, que la moral tiene un componente de control ya que ésta "es un sistema que los individuos no controlan, pero que trata de controlarlo. La moralidad ejerce esa tiranía haciendo que las personas se sientan incómodas, culpables quizá, a causa de unas acciones que, en otro caso, les parecerían naturales o inofensivas" (Haydon, 2003, p. 92).

No obstante, el lector estará de acuerdo que en todo grupo social se necesitan normas de conducta que regulen la convivencia. Eso ocurre incluso en las instituciones educativas y en tal caso "el mantenimiento de esas reglas no puede considerarse como una imposición, y nadie lo interpretará como una cuestión de moralidad" (Haydon, 2003, p. 90). Decía Savater (2012) que en un mundo ideal, "si predominasen aquellos valores que deseamos que prevalezcan, si... los seres humanos fuesen sinceros, tolerantes, solidarios,...no les haría falta educarles en esas cosas" (p. 25). No se busca exigir que los docentes sean un dechado de santidad, aunque sí se espera que los educadores "tengan un sentido claro de los valores morales y estén preparados para vivir de acuerdo con ellos" (Haydon, 2003, p. 91). Es más, se espera que los educadores también estén preparados para orientar a otros para vivir de acuerdo con sus propios valores morales. Aunque algunos pueden llegar a pensar que sería mejor prescindir de la moral, al menos una moralidad mínima es necesaria para que las personas puedan convivir. Recordando a Kant, Savater (2002) observa que incluso los demonios necesitarían reglas morales para vivir como comunidad y que aún en los grupos de delincuentes hay reglas, de lo contrario cada quien haría lo que quisiera a su manera (p. 27). El hecho que la moral implica control e imposición no deja de crear cierta aversión; aunque, si la moral es buena para regular el comportamiento y la forma de pensar, sería también buena idea que la educación y los educadores se ocuparan de ella. 
Pareciera que el comportamiento y la forma de pensar están determinados por más de una motivación, no sólo por la moral. Antes se citó a Gevaert (2008) para quien una actuación está precedida por una decisión y una motivación. También se dijo que las creencias religiosas, el sentimiento de culpabilidad y la creencia en el pecado hacen que algunas personas se sientan obligadas a actuar de cierto modo según la voluntad divina. Otras personas se comportan y actúan motivadas por el deber; aunque si una persona actúa únicamente bajo el sentido del deber, como la obediencia, sería peligroso si a quienes obedece tiene motivaciones inmorales como se ejemplificó antes. Además, hay personas altruistas cuyas acciones se mueven por la compasión hacia los demás. Se debe notar que la compasión se rige por los sentimientos, lo cual puede ser un obstáculo para actuar apropiadamente cuando los sentimientos opacan la capacidad de razonar ante una situación en la cual los valores morales se ven comprometidos.

La razón también es una motivación para la actuación y el pensamiento. En este sentido, Haydon (2003) explica que "la motivación moral está informada por la razón: exige que las personas piensen por sí mismas acerca de lo que está bien y lo que está mal, sin seguir acríticamente a los demás" (p. 107). Pensar por uno mismo implica que exista un proceso de discernimiento y juicio sobre la situación en su totalidad de manera que la decisión y actuación sea la más apropiada. Haydon (2003) agrega que la motivación moral implica necesariamente atender a la justicia la cual, al mismo tiempo, exige que actuemos de una manera determinada, no porque exista una inclinación hacia ello ni por altruismo, sino porque es justo actuar de esa manera. La idea de justicia implica que la persona sea autónoma, no autómata.

Lo anterior representa una alternativa a la educación funcionalista y tradicional que no pretende la transformación de la persona ni la sociedad. Una educación que se caracterice por cultivar la motivación moral será aquella que cree los espacios para que los estudiantes aprendan a decidir y actuar no basados en el deber ser, los sentimientos o las creencias religiosas y dogmas, sino basados en el razonamiento y la justicia. Se trata de un tipo de educación que genere espacios pedagógicos en los que la imparcialidad y la objetividad en la forma de ver las cosas precedan las decisiones o actuaciones y que éstas, a la vez, sean las más apropiadas, lo que más conviene hacer, o no hacer, entre varias posibilidades. No se trata de pasar la vida en las aulas haciendo juicios morales sobre otros, sino de ponerse en el lugar de los demás en contextos y situaciones que permitan reflexionar sobre lo que está bien hacer o no y por qué. Tampoco es el propósito de hacer juicios morales sobre las personas, sino sobre la actuación contextualizada. Contribuir a que las personas actúen y decidan haciendo uso de la razón, es algo que la educación y los educadores sí pueden hacer desde las aulas.

\section{6. ¿Cómo formar en valores?}

Ante las condiciones decadentes de esta sociedad en la que vivimos, no es 
apropiado ni pertinente que las instituciones educativas y los profesores continúen transmitiendo conocimiento de la misma manera que hace más de medio siglo. Sería más grave aún creer que basta con hablar sobre valores y la moral frente a un grupo de estudiantes para que ellos memoricen el contenido y que por algún milagro de la vida tarde o temprano los pongan en práctica. Transmitir conocimiento recuerda el conductismo en el que los estudiantes esperan de forma pasiva la información que han de memorizar. Transmitir conocimiento también recuerda el adoctrinamiento el cual pretende que las personas piensen de una manera determinada sin ser capaces de cuestionar o someter las ideas y comportamiento al escrutinio racional. Una educación de esta naturaleza sólo cabría en las sombrías y tenebrosas épocas de las tiranías y las dictaduras militares durante las cuales no existía forma de cuestionar a quienes ostentaban el poder. Como bien lo apunta Savater (2002), "no hace falta preparación ninguna para vivir en una dictadura, no hace falta preparación ninguna para vivir bajo un tirano...cuanto menos valores se tengan, mejor se adaptará uno a vivir bajo el tirano (p. 27). La sociedad actual necesita que la educación se ocupe de la reflexión sobre valores y que desplace la mera transmisión del conocimiento y el adoctrinamiento.

Se mencionó al inicio que la educación tiene la responsabilidad de transmitir no sólo destrezas, sino también formar en valores. Savater (2002) señala que la tarea de la educación, aunque limitada, trata de inculcar elementos de la cultura en forma consciente, deliberada y selectiva tanto de aquello que se cree importante como de aquello que se debería dejar atrás. Para este autor, "no se trata de que si no enseñamos nosotros nada, el niño no vaya a prender nada, es que si no le enseñamos las cosas que son dignas de ser enseñadas, aprenderán las otras" (Savater, 2002, p. 24). Es decir, aunque la escuela no haga esa labor intencionada de formar en valores, de todas maneras los estudiantes aprenderán los elementos culturales a su alrededor aún y cuando sean perniciosos y perversos.

Por tanto, las instituciones educativas y los educadores deben jugar un rol protagónico en la acción transformadora de sus estudiantes mediante una educación que retome de forma seria la formación en valores. Para que los estudiantes se vuelvan agentes transformadores de su entorno hace falta algo más que formar hábitos, inculcar disciplina y obediencia. Los estudiantes necesitan conocer sobre valores y ser capacitados para reflexionar sobre el sistema de valores vigente en la sociedad así como comprender las diferencias relativas a dichos valores. Los estudiantes hoy en día necesitan desarrollar conocimiento acerca de los valores y "la única manera de que aumente la probabilidad de que una cantidad importante de personas adquiera esos conocimientos es a través de la educación formal" (Haydon, 2003, p. 180). Ese conocimiento es crucial para reflexionar de forma crítica en una sociedad como la nuestra en la que impera el conflicto, la decadencia, el maltrato y la violencia. La contribución de las instituciones educativas y los educadores no será entonces la de transmitir y enseñar todo, sino la de "facilitar la práctica en contextos en los que las personas puedan reflexionar sobre sus formas concretas de pensar" 
(Haydon, 2003, p. 175). La reflexión supera la transmisión de conocimiento. La mera transmisión de ideas y el adoctrinamiento riñe con los valores otorgados a la razón y la independencia al pensar. Estos últimos son valores que han de cultivarse en una sociedad como la nuestra en la cual se esperaría que las personas tengan la capacidad de actuar y decidir con autonomía.

La sociedad salvadoreña se beneficiaría en gran manera de contar con, además de altruistas, personas que se caractericen por actuar en forma razonable ante problemas morales del día a día. En una sociedad con diversidad de opiniones sobre los valores morales, es necesario que exista la capacidad de sentar posiciones y proponer soluciones con conocimiento, no sólo a partir de los sentimientos. No parece que el deseo de ayudar a otros de la misma especie sea la característica que nos distinga como seres humanos. Lo que en realidad nos hace diferentes a otras especies es que podemos razonar sobre diferentes situaciones, problemas, controversias y posibilidades lo cual nos permita tomar decisiones y actuar con justicia: ponernos en el lugar de los demás. No obstante, como bien lo señala Haydon (2003), "una persona no puede ser justa sin tener y utilizar una concepción de la justicia, por lo que no hay manera de que alguien pueda ser inconscientemente justo (p. 161). Para actuar con justicia, la persona tiene que tener conciencia de las necesidades y problemas de los demás para luego ser capaz de decidir y actuar. Está claro que haya personas que son compasivas y altruistas y que actúan así porque han cultivado esas virtudes, aunque es más probable que quien actúa de forma compasiva lo haga por naturaleza. Sin embargo, para actuar con justicia, tolerar las diferencias y respetar las opiniones de otros se requiere de condiciones para reflexionar, dialogar y practicar tales cualidades.

Aunque desafiante, el aporte que las instituciones educativas y los educadores pueden hacer en cuanto a la formación en valores es crear esas condiciones para la reflexión crítica sobre situaciones en las que se ve comprometida la moralidad. ¿Cómo pueden los estudiantes reflexionar en forma crítica si no es mediante la práctica de la reflexión crítica? Los estudiantes tienen que hablar sobre temas y situaciones que se viven en la sociedad y en las que ellos están inmersos. El aborto, la sexualidad, la pena de muerte, la violencia, la corrupción, y muchos otros temas que generan conflicto deben ser sujetos de la reflexión, la crítica, el enjuiciamiento, a la toma de postura y a la decisión informada. En una sociedad como la nuestra, es imperante que las personas aprendan a deliberar para producir cambios positivos en el presente o evitar males en el futuro sin tener que recurrir a la violencia. En esta línea, Savater (2002) sostiene que "en primer lugar, educar es desarrollar la capacidad de deliberar. . . ser capaz, insisto, de ser un ser racional en cuanto a los medios y también un ser razonable en cuanto a los fines" (p. 29). Al igual que se crean situaciones y condiciones para que los alumnos practiquen y desarrollen competencias para el trabajo, se deben crear condiciones que ejerciten la reflexión, la tolerancia, el respeto a la diversidad de opiniones, la autonomía y la independencia de pensamiento. Ahora, ¿cómo hacer esto en el aula? 
Las instituciones educativas constituyen, quizá, el mejor espacio para que mediante el diálogo y el consenso se pueda ejercitar la reflexión, la tolerancia y el respeto a las opiniones de los demás. Sobre este punto, Savater (2002) comenta que las opiniones no pueden ser castillos o fortaleza medievales en los cuales no hay posibilidad de entrar o salir. Por el contrario, él sostiene que "las opiniones son aquellos espacios en los cuales uno sale a buscar a los otros y ofrece una línea de interpretación que se contrasta con otra, pero no simplemente que uno ofrece algo que uno es" (p. 36). Ahora bien, el contrastar opiniones podría hacer surgir la idea de que se está intentando encontrar la respuesta correcta. Se podría incluso pensar que es parte de la naturaleza humana categorizar este o aquel punto de vista o creencia bajo lo correcto o incorrecto. El problema es que definir lo correcto de lo incorrecto implica que hay uno o varios que están equivocados, aunque al final los resultados pudiesen demostrar lo contrario. No tiene que ser de esta manera, cuando encontrar soluciones se quiere.

Para comprender una situación, un problema moral o una necesidad es necesario crear los espacios pedagógicos para reflexionar sobre ellos. Sin embargo, para reflexionar antes se debe escuchar y considerar los distintos puntos de vista a la vez que se pone en práctica la tolerancia y el respeto por lo que tengan que decir los demás. Al respecto, Haydon (2003) sostiene que el propósito de la acción educativa no es únicamente lograr que los estudiantes sean conscientes de lo que les gustaría o no si estuvieran en el lugar de otros "sino en procurar dar coherencia al propio pensamiento, y la capacidad para lograrlo, y de preocuparse por lograrlo, es también algo que la educación tiene que promover" (p. 177). Para algunos educadores, la reflexión podría lograrse a partir de la discusión y el debate. No obstante, aunque éstos puede conducir a una mejor comprensión de los diferentes puntos de vista, se corre el riesgo de generar discusiones y debates que a la larga afecten el ejercicio de la tolerancia y el respeto hacia otros en la medida en que el enfrentamiento no sea bien manejado por el docente. Algo como eso iría más en la línea de querer confirmar una verdad o encontrar la postura correcta.

Existen otras alternativas racionales como el diálogo y el consenso. El aula es un espacio ideal en el que se pueden desarrollar contextos que permita a los estudiantes expresar sus opiniones y objeciones con libertad con el propósito de llegar a un acuerdo práctico sobre qué se puede hacer ante una situación dada, sin que ello implique que esa es la respuesta correcta. La labor de los docentes es justamente promover las capacidades intelectuales y las disposiciones para involucrarse en un diálogo constructivo en vez de los debates por bandos. No hay razón para establecer de antemano que únicamente puede haber dos respuestas, de las cuales una contiene la verdad o una es la correcta. Se debe subrayar la necesidad de comprender y consensuar, pero para que ello suceda, antes se debe dialogar y escuchar a los demás así como aprender a tolerar y respetar, no a los demás, sino a las diferencias. 


\section{Conclusión}

Se ha repetido en muchos lugares y en muchas ocasiones que la educación tiene la misión de preparar a los futuros ciudadanos. Esa tarea no se hará por completo si los futuros ciudadanos se preparan sólo para el campo laboral y no para reflexionar sobre su propio sistema de valores morales. Al igual que las destrezas para el mundo laboral son practicadas, así también el pensamiento crítico, la reflexión, la tolerancia y el respeto deben ser ejercitados para la toma de decisiones razonadas frente a situaciones en los que los valores morales se vean comprometidos. Acá se acepta la idea de que no hay medio mejor que la educación, las instituciones educativas y los profesores para que las personas aprendan a dialogar en forma razonada sobre valores morales, sobre lo que está bien, lo que está mal o cómo se debe actuar, sin que ello sea una preferencia personal o un sometimiento irreflexivo a la tradición, dogmas y creencias. Hacer este aporte a la sociedad salvadoreña es algo que se espera y que se debe demandar de la educación que brindamos a nuestros estudiantes. Esta es la tarea que todos los educadores aún tenemos pendiente.

\section{Referencias}

Azofeifa, I. F. (1979). Humanismo crítico. San José: Editorial Universidad de Costa Rica.

Durkheim, É. (1947). La educación moral. Buenos Aires: Losada.

Ferraz Lorenzo, M. (2012). De la pedagogía oficial a la pedagogía crítica. Revista Iberoamericana de Educación. 58(4), 2-16.

Gevaert, J. (2008). El problema del hombre: introducción a la antropología filosófica. Salamanca: Ediciones Sígueme.

Haydon, G. (2003). Enseñar valores: un nuevo enfoque. Madrid: Ediciones Morata S. L.

Levine, T. H. (2010). Socializing future social studies teachers and K-12 students: whether, when, and why. The Social Studies, 10, 69-74.

Sacristán, J., \& Pérez, A. (2003). Comprender y transformar la enseñanza. Madrid: Morata.

Savater, F. (2002). La educación y los valores de la ciudadanía. En C. Ornelas, Valores, calidad y educación . (21-39). México: Editorial Santillana, S.A. 